\title{
Effects of rosiglitazone on the growth and lymphangiogenesis of human gastric cancer transplanted in nude mice
}

\author{
FANG-ZHI CHEN ${ }^{1,2^{*}}$, XI-MING MO ${ }^{4 *}$, QING-PING WANG ${ }^{3}$, JUN LI $^{1}$ and LI ZHANG ${ }^{1}$ \\ ${ }^{1}$ Department of Gastroenterology, The Second Affiliated Hospital of University of South China, Hengyang, \\ Hunan 421001; ${ }^{2}$ Department of Gastroenterology, The Shaoxing Hospital of China Medical University, \\ Shaoxing, Zhejiang 312030; ${ }^{3}$ Department of Clinical Laboratory, The Shaoxing Hospital of China \\ Medical University, Shaoxing, Zhejiang 312030; ${ }^{4}$ Department of Clinical Laboratory, The Second \\ Xiangya Hospital of Central South University, Changsha, Hunan 410011, P.R. China
}

Received May 30, 2013; Accepted July 19, 2013

DOI: $10.3892 /$ or.2013.2704

\begin{abstract}
Gastric cancer mainly metastasizes via lymphatic vessels. Thus, it is critical to identify efficacious chemopreventive agents for lymphangiogenesis. The present study was undertaken to explore the effects of rosiglitazone (ROSI) on the growth and lymphangiogenesis of human gastric cancer. We established a model of gastric cancer by subcutaneously inoculating the human gastric cancer cell line SGC-7901 into nude mice. Mice were randomly divided into 4 groups and each group received a different agent by oral gavage. The control group received normal saline and treatment groups received different doses of ROSI once every 2 days. The growth of the tumor in vivo was assessed by measuring tumor volume. After 42 days, the mice were sacrificed and the tumors were removed. H\&E staining was used to observe the histomorphological features; immunohistochemistry staining for lymphatic vessel density (LVD) was used to evaluate tumor lymphangiogenesis, RT-PCR was performed to determine the mRNA expression of vascular endothelial growth factor $\mathrm{C}$ (VEGF-C) and VEGF receptor-3 (VEGFR-3), and western blotting was used to detect the protein expression of VEGF-C and VEGFR-3. Compared with the control group, all treatment groups had smaller tumor volume and higher tumor growth inhibitory rate every day. The number of typical tumor cells in the control group was higher compared to that in the treatment groups, and the highest level of LVD was found in the control group. Furthermore, both the expression of VEGF-C and VEGFR-3 mRNA and proteins in the control group were
\end{abstract}

Correspondence to: Professor Li Zhang, Department of Gastroenterology, The Second Affiliated Hospital of University of South China, Hengyang, Hunan 421001, P.R. China

E-mail: wangyulin774@163.com

${ }^{*}$ Contributed equally

Key words: rosiglitazone, peroxisome proliferator-activated receptor $\gamma$, gastric cancer, lymphangiogenesis significantly higher compared to those in the treatment groups. Markedly, these changes were correlated in a dose-dependent manner with ROSI. These results demonstrated that, through simultaneously blocking the expression of VEGF-C and VEGFR-3, ROSI suppresses lymphangiogenesis. This may represent a powerful therapeutic approach for controlling gastric cancer cell growth and metastasis.

\section{Introduction}

Gastric cancer is the fourth most common cancer and remains the second most common cause of cancer-related mortality in the world although its incidence and mortality has declined over the last half-century $(1,2)$. Surgery is the most common treatment for gastric cancer. However, gastric cancer is difficult to cure unless it is found in an early stage (before it has begun to spread). Unfortunately, most cancer patients present with metastasis or advanced disease when the diagnosis is made. As a result, surgical interventions are currently curative in less than $40 \%$ of cases (3), and in cases of metastasis, may only be palliative. Generally, these patients should receive systemic chemotherapy apart from surgical resection. Nevertheless, gastric cancer has not been particularly sensitive to these drugs, and chemotherapy, if used, has usually served to merely reduce the size of the tumor, relieve symptoms of the disease and increase survival time.

Metastatic spread of tumor cells often occurs via the lymphatic vessels (4). Tumor-associated lymphatic vessels, also referred to as tumor lymphangiogenesis, act as a conduit by which disseminating tumor cell access regional lymph nodes and form metastases (5-7). Thus, tumor lymphangiogenesis plays an important role in promoting tumor metastasis. Since lymph node metastasis is an early event in the metastatic process (8), use of chemopreventive agents to block lymphangiogenesis pathways seems to be an attractive anticancer treatment strategy.

Rosiglitazone (ROSI), a synthetic peroxisome proliferatoractivated receptor $\gamma$ (PPAR $\gamma)$ agonist, is a member of the thiazolidinedione (TZD) agents. These PPAR $\gamma$ ligands were clinically used as antidiabetic drugs which could attenuate the insulin resistance associated with obesity, hypertension, 
and impaired glucose tolerance in humans (9). Recent studies suggested that ROSI have significant anticancer effects on various human malignant tumor cells in vitro, including gastric, breast, colorectal, bladder, adrenocortical and pancreatic cancer types (10-15). In vivo, ROSI also exhibited antitumor activities in the prevention of lung, breast, prostate, and adrenocortical cancer (16-19). These studies show that ROSI exerts its anti anticancer effect by inducing cancer cell growth arrest, differentiation and apoptosis, or by inhibiting neovascularization of cancer and suppressing tumor migration.

However, the roles of ROSI in tumor lymphangiogenesis and lymphatic metastasis were unclear. Since nearly $85 \%$ of tumors were accompanied by lymph node metastasis in gastric cancer patients present with advanced stage (20), in the present study, we investigated for the first time the effect of ROSI on the growth and lymphangiogenesis of human gastric cancer transplanted in nude mice, so as to explore whether ROSI is a potential anti-lymphangiogenic agent for gastric cancer therapeutic strategy.

\section{Materials and methods}

Cells and cell cultures. Human gastric cancer cell line, SGC-7901, was obtained from the Type Culture Collection of the Chinese Academy of Sciences (Shanghai,China). SGC-7901 cells were cultured in RPMI-1640 medium (Gibco-BRL, Carlsbad, CA, USA) containing $10 \%$ fetal bovine serum (FBS) (Hangzhou Sijiqing Biological Engineering Materials Co., Ltd, China) and $1 \%$ antibiotics $(100 \mathrm{U} / \mathrm{ml}$ penicillin $\mathrm{G}$, $100 \mathrm{U} / \mathrm{ml}$ streptomycin sulfate). Cells were maintained in logarithmic growth in a humidified atmosphere of $5 \% \mathrm{CO}_{2}$ at $37^{\circ} \mathrm{C}$. Adherent tumor cells were harvested from subconfluent cultures by a brief exposure to trypsin [containing $0.25 \%$ phosphate buffered saline (PBS) and $0.05 \%$ ethylenediaminetetraacetic acid (EDTA)], trypsinization was stopped with medium containing $10 \%$ serum, and the cells were washed once and resuspended in serum-free medium. Trypan blue staining was used to assess cell viability, and only single-cell suspensions of $>95 \%$ viability were used for injections.

Animal experiment procedure. Thirty-two BALB/C male nude mice weighing 16-18 $\mathrm{g}$ at 6-8 weeks of age were purchased from Beijing Laboratory Animal Research Center (Beijing, China). All procedures involving mice were approved by the University of South China Animal Management Committee and Beijing City Animal Management Committee. Mice were kept under specific pathogen-free conditions in accordance with the NIH guidelines for the care and use of laboratory animals, fed a standard rodent chow and maintained in a temperature-controlled $\left(23-25^{\circ} \mathrm{C}\right)$ facility with a strict $12 \mathrm{~h}$ light/dark cycle and given free access to food and water. Each mouse was inoculated with a subcutaneous injection of SGC-7901 cells $\left(2 \times 10^{6}\right.$ in $0.2 \mathrm{ml}$ PBS) on the right side of the back. One day after inoculation of tumor cells, the mice were randomly divided into 4 groups of 8 mice and each group received a different dose of ROSI (Cayman Chemical Company, Ann Arbor, MI, USA), i.e., group A (control group) received normal saline, group B received ROSI $50 \mathrm{mg} / \mathrm{kg}$, group C received ROSI $75 \mathrm{mg} / \mathrm{kg}$ and group D received ROSI $100 \mathrm{mg} / \mathrm{kg}$. Each group was treated with the same volume
$(0.2 \mathrm{ml})$ by oral gavage once every 2 days for 42 days. After 42 days, the mice were sacrificed and the gastric cancer tissues were stored at $-70^{\circ} \mathrm{C}$ for further analysis.

Tumor growth assessment. To assess the tumor growth, tumor size was measured with a sliding caliper for a maximal diameter (a) and a minimal diameter (b) at 2, 7, 12, 17, 22, 27, 32, 37 and 42 days after tumor cell inoculation, and then the volume $(\mathrm{V})$ and the tumor growth inhibition rate (IR) were calculated using the following formula: $\mathrm{V}=\mathrm{ax} \mathrm{b}^{2} / 2$; IR $(\%)=(1-\mathrm{V}$ of ROSI treatment group/V of control group) $\times 100 \%$.

Hematoxylin and eosin $(H \& E)$ staining for histomorphological examination. Tumor tissues were fixed in $10 \%$ neutral buffered (formalin) for $24 \mathrm{~h}$ and then embedded in paraffin. The paraffinembedded tissue blocks were cut into $4 \mu \mathrm{m}$ sections. After baking at $65^{\circ} \mathrm{C}$ for $60 \mathrm{~min}$, the sections were de-paraffinized and hydrated gradually, and examined after routine $\mathrm{H} \& \mathrm{E}$ staining. The histomorphology of tumor cells was observed by light microscopy at a magnification of $\mathrm{x} 400$.

Immunohistochemistry staining for lymphatic vessel density $(L V D)$. In order to evaluate tumor lymphangiogenesis, we performed immunohistochemistry staining using D2-40 antibody for LVD. The LVD was defined as the average number of D2-40 positive vessels. In brief, formalin-fixed, paraffinembedded tissue blocks were cut into $4 \mu \mathrm{m}$ sections and baked at $65^{\circ} \mathrm{C}$ for $60 \mathrm{~min}$. The sections were de-paraffinized and hydrated gradually, then heated in a microwave oven for $15 \mathrm{~min}$ to retrieve antigens. Endogenous peroxidase was blocked with $3 \%$ hydrogen peroxide methanol for $15 \mathrm{~min}$ at room temperature. After washing with PBS (0.01 M, pH 7.4) for $3 \times 5 \mathrm{~min}$, the tumor sections were incubated with normal bovine serum for $30 \mathrm{~min}$ at room temperature to eliminate nonspecific staining. Mouse anti-human D2-40 antibody (1:200 dilution; Santa Cruz Biotechnology, Inc., Santa Cruz, CA, USA) was incubated with the sections overnight at $4^{\circ} \mathrm{C}$. After washing with $0.01 \mathrm{M}$ PBS for $3 \times 5 \mathrm{~min}$, tissue sections were treated with goat anti-mouse IgG secondary antibody (Dako, Denmark) for $1 \mathrm{~h}$ at room temperature. Finally, tissue sections were immersed in 3-amino-9-ethyl carbazole (DAB) (Sigma-Aldrich) for 5-10 min at room temperature, washed with water, and then counterstained with $10 \%$ Mayer's hematoxylin. Negative and positive controls were used simultaneously to ensure the specificity and reliability of the staining process. The negative controls were performed by substituting PBS for the primary antibody, and a positive section supplied by the manufacturer of the staining kit was registered as a positive control. Sections were observed under a microscope after being mounted.

All sections were coded and evaluated by 2 experienced pathologists. All the stained vessels with brown by D2-40 immunostaining were observed as typically positive lymphatic vessels in thin-walled and tube-like structures exhibiting a distinct inner cavity and devoid of red blood cells. LVDs (D2-40-positive vessels) were calculated as described by Ohno et al (21). Briefly, sections were first scanned at a low magnification (x40) to identify lymphatic vessel hot spots. Areas of the greatest vessel density were then examined and counted under a higher magnification (x200), and the average value of the 5 measurements was used for data analysis. 
Table I. Tumor volume and tumor growth inhibition rate at day $42(n=8)$.

Group

Tumor volume $\left(\mathrm{mm}^{3}\right)$

Inhibition rate $(\%)$

A (normal saline, $0.2 \mathrm{ml} / 2$ days $)$
B (50 mg/kg ROSI, $0.2 \mathrm{ml} / 2$ days)
C (75 mg/kg ROSI, $0.2 \mathrm{ml} / 2$ days)
D (100 mg/kg ROSI, $0.2 \mathrm{ml} / 2$ days)

$745.46 \pm 10.64$

$606.65 \pm 10.64^{\mathrm{a}, \mathrm{b}}$

$406.30 \pm 10.86^{\mathrm{a}, \mathrm{c}}$

$18.62 \pm 0.34^{\mathrm{b}}$

$\mathrm{D}(100 \mathrm{mg} / \mathrm{kg}$ ROSI, $0.2 \mathrm{ml} / 2$ days $)$

$304.59 \pm 11.92^{\mathrm{a}}$

$45.49 \pm 0.67^{\mathrm{c}}$

$59.14 \pm 1.02$

${ }^{\mathrm{a}} \mathrm{p}<0.0001$, compared with group $\mathrm{A} ;{ }^{\mathrm{b}} \mathrm{p}<0.0001$, compared with group $\mathrm{C}$ and $\mathrm{D} ;{ }^{\mathrm{c}} \mathrm{p}<0.0001$, compared with group D. ROSI, rosiglitazone.

RT-PCR assay for vascular endothelial growth factor (VEGF)-C and VEGF receptor-3 (VEGFR-3) mRNA expressions. Tumor tissues were homogenized in a TissueLyzer homogenizer (Qiagen, Hilden, Germany) with 5-mm steal beads. Total RNA was extracted using TRIzol reagent (Omega, USA) according to the manufacturer's instructions. Reverse transcription was performed using $1.0 \mu \mathrm{g}$ total RNA and the reverse transcription system (Sangon Biotech Co., Ltd., Shanghai, China). PCR amplification was produced by a Biometra TGradient Thermoblock (Biometra, Göttingen, Germany) in a reaction mixture of $25 \mu 1$ reaction volumes containing amplification primers. A $1 \mu \mathrm{l}$ volume of cDNA was used in each amplification reaction. The sequences of specific primers were: VEGF-C mRNA forward, 5'-GCTT CTTGTCTCTGGCGTGTTC-3' and reverse, 5'-AAACTGAT TGTGACTGGTTTGG-3'; VEGFR-3 mRNA forward, 5'-AGA TGCAGCCGGGCGCTGCGCT-3' and reverse, 5'-TAGGCT GTCCCCGGTGTCAATC-3'; $\beta$-actin mRNA forward, 5'-TC GTGCGTGACATCAAAGAG-3' and reverse, 5'-TGGACAG TGAGGCCAAGATG-3'. Amplification was performed as follows: $94^{\circ} \mathrm{C}, 5 \mathrm{~min} ; 94^{\circ} \mathrm{C}, 15 \mathrm{sec} ; 68^{\circ} \mathrm{C}, 3 \mathrm{~min}$ and $68^{\circ} \mathrm{C}$, $3 \mathrm{~min}$ for 35 cycles. The PCR products were $583 \mathrm{bp}$ for VEGF-C; 143 bp for VEGFR-3 and 429 bp for $\beta$-actin. These PCR products were electrophoresed on a $1.5 \%$ agarose gel and visualized by ethidium bromide staining. Densitometries of the bands were scanned and quantified by the LabWork software (LabWork ${ }^{\mathrm{TM}}$ version 3.00; Upland, CA, USA). Data were normalized against those of the corresponding $\beta$-actin bands. Results were expressed as fold increase over $\beta$-actin.

Western blotting for VEGF-C and VEGFR-3 protein expressions. The cell proteins were extracted according to NE-PER Nuclear and Cytoplasmic Extraction Reagents kit (Pierce Biotechnology, Inc., Rockford, IL, USA). The protein concentration of each sample was determined by the Bradford assay. Twenty micrograms of proteins of different groups were separated in $10 \%$ SDS-PAGE, and transferred onto PVDF membrane (Amersham Pharmacia Biotech). The membrane was blocked with $5.0 \%$ nonfat milk in PBS at $4^{\circ} \mathrm{C}$ for $1 \mathrm{~h}$ and then incubated with rabbit anti-human VEGF-C antibody (1:40 dilution), rabbit anti-human VEGFR-3 antibody (1:100 dilution) (both from Santa Cruz Biotechnology, Inc.) or mouse anti-human $\beta$-actin (1:200 dilution; Xiaxin, China) overnight at $4^{\circ} \mathrm{C}$. After washing 3 times with $0.1 \%$ Tween- 20 in Trissaline, the membranes were incubated with goat anti-mouse or rabbit $\operatorname{IgG}$ conjugated with horseradish peroxidase at 1:1,000 in PBS for $1 \mathrm{~h}$ at room temperature. Blots were processed

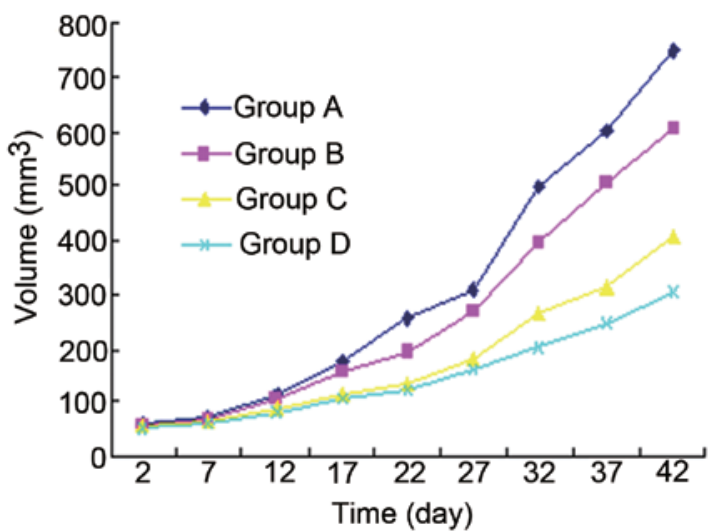

Figure 1. The inhibitory effects of rosiglitazone (ROSI) on the growth of human gastric cancer transplanted in nude mice. One day after inoculation of tumor cells, mice were randomly divided into 4 groups and each group was treated with a $0.2 \mathrm{ml}$ different agent by oral gavage once every 2 days for 42 days. Tumor volume was measured at 2, 7, 12, 17, 22, 27, 32, 37 and 42 days after tumor cell inoculation. Group A (control group), mice were treated with normal saline; group B, mice were treated with ROSI $50 \mathrm{mg} / \mathrm{kg}$; group G, mice were treated with ROSI $75 \mathrm{mg} / \mathrm{kg}$; group D, mice were treated with ROSI $100 \mathrm{mg} / \mathrm{kg}$.

using an ECL kit (Santa Cruz Biotechnology, Inc.) and exposed to X-ray film. Densitometries of the bands were scanned and quantified by the LabWork software (LabWork ${ }^{\mathrm{TM}}$ version 3.00). Data were normalized against those of the corresponding $\beta$-actin bands. Results were expressed as fold increase over $\beta$-actin.

Statistical analyses. All experiments were repeated at least 6 times. SPSS 13.0 was used for the statistical analyses. Data are presented as the means $\pm \mathrm{SD}$. Comparisons were made using a one-way ANOVA or paired t-test. $\mathrm{p}<0.05$ was considered to indicate statistically significant differences.

\section{Results}

Effects of ROSI on the growth of human gastric cancer transplanted in nude mice. Fig. 1 shows the effects of ROSI on the growth of human gastric cancer transplanted in nude mice in a dose-dependent manner. Before transplantation of human gastric cancer into nude mice, the weight of nude mice had no significant difference among each group ( $\mathrm{p}>0.05)$. Following transplantation, the volume of the tumor in nude mice increased gradually with time. However, compared with the volumes of tumor in the group treated with normal saline 

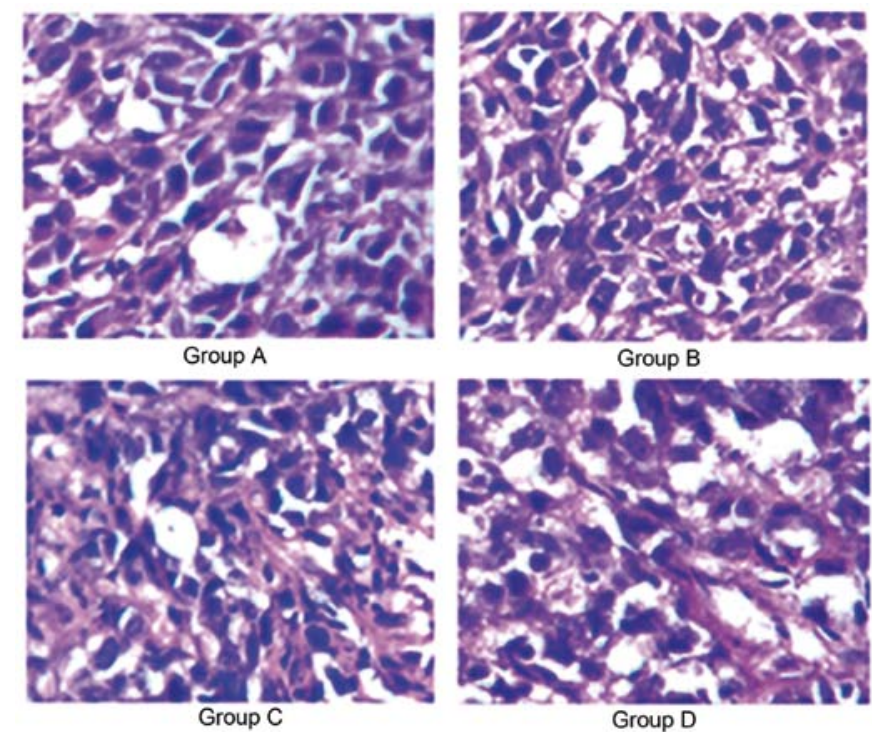

Figure 2. Representative microscopic view of the hematoxylin and eosin (H\&E) staining of tumor cells of human gastric cancer transplanted in nude mice. One day after inoculation of tumor cells, mice were randomly divided into 4 groups and each group was treated with a $0.2 \mathrm{ml}$ different agent by oral gavage once every 2 days for 42 days. The sections of tumor tissues were prepared from nude mice at 42 days after inoculation of tumor cells and examined with a microscope at x400 magnification. Group A (control group), mice were treated with normal saline; group B, mice were treated with rosiglitazone (ROSI) $50 \mathrm{mg} / \mathrm{kg}$; group C, mice were treated with ROSI $75 \mathrm{mg} / \mathrm{kg}$; group D, mice were treated with ROSI $100 \mathrm{mg} / \mathrm{kg}$.

(group A), those in other groups treated with different doses of ROSI were gradually attenuated with the increasing dose of ROSI every day. After 42 days of transplantation, the tumor volume in the groups treated with different ROSI doses were all significantly smaller than those in the group treated with normal saline. Correspondingly, the tumor growth inhibition rate gradually increased with the increasing dose of ROSI every day and reached the maximum at day 42 . These results demonstrated that ROSI inhibits the tumor growth of human gastric cancer in a time- and dose-dependent manner.

The tumor volume changes and tumor growth inhibition rate at day 42 are shown in Table I.

Effects of ROSI on the histomorphology of gastric cancer cells. To observe the histomorphological changes of gastric cancer cells, H\&E staining was performed on the tumor tissue prepared from nude mice after 42 days of transplantation with human gastric cancer. The morphology of tumor cells was characterized by both nuclear and cytoplasmic alteration. Nuclear features included the presence of peculiar enlargement with hyperchromatism, irregularity of outline, and chromatin clumping or smudging. Cytoplasmic alterations included abundant cytoplasm, vacuolation, or foam cell formation.

Our findings showed that the number of typical tumor cells in the group treated with normal saline (group A) was more than that in other groups treated with different ROSI doses. Fig. 2 shows the representative microscopic view of the H\&E staining for tumor cells in nude mice treated with normal saline and different ROSI dose at a magnification of $\mathrm{x} 400$, which illustrated that ROSI inhibited tumor cell formation in a dose-dependent manner.
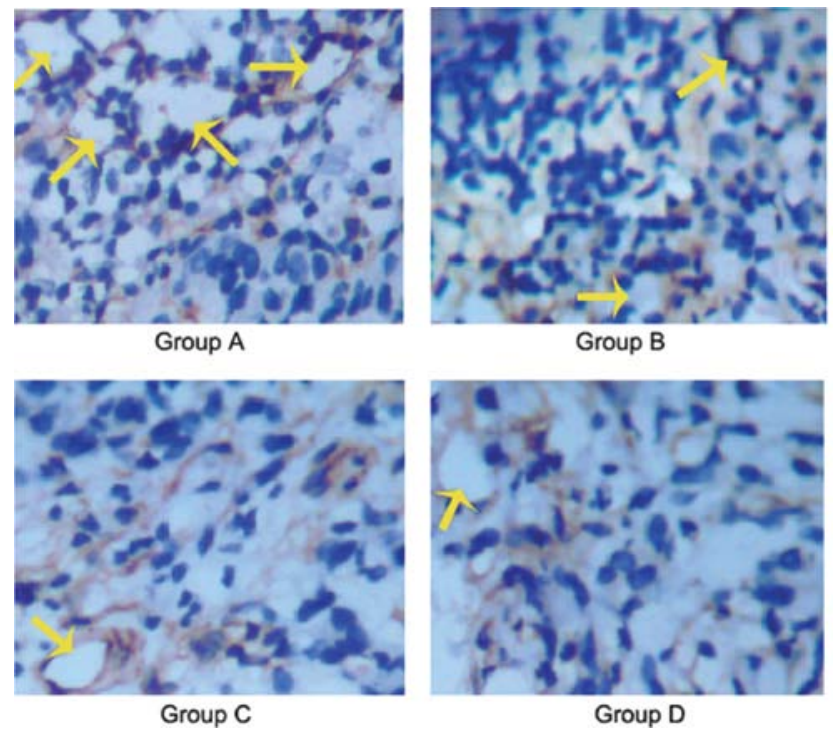

Figure 3. Immunohistochemical staining for lymphatic vessel density (LVD) human gastric cancer transplanted in nude mice. One day after inoculation of tumor cells, mice were randomly divided into 4 groups and each group was treated with a $0.2 \mathrm{ml}$ different agent by oral gavage once every 2 days for 42 days. The sections of tumor tissues were prepared from nude mice at 42 days after inoculation of tumor cells. Immunohistochemical staining was performed using a specific and sensitive immunohistochemical marker of lymphatic endothelial cells, D2-40. Present sections were examined with a microscope at $\mathrm{x} 400$ magnification. Yellow arrows indicate typically positive lymphatic vessels. Group A (control group), mice were treated with normal saline; group B, mice were treated with rosiglitazone (ROSI) $50 \mathrm{mg} / \mathrm{kg}$; group C, mice were treated with ROSI $75 \mathrm{mg} / \mathrm{kg}$; group D, mice were treated with ROSI $100 \mathrm{mg} / \mathrm{kg}$.

Table II. The average value of D2-40-positive vessels in 5 hot spot areas at x200 magnification (LVD) $(n=8)$.

\begin{tabular}{ll}
\hline Group & \multicolumn{1}{c}{ LVD } \\
\hline A (normal saline, $0.2 \mathrm{ml} / 2$ days $)$ & $9.62 \pm 1.19$ \\
B (50 mg/kg ROSI, $0.2 \mathrm{ml} / 2$ days) & $6.62 \pm 0.80^{\mathrm{a}, \mathrm{b}}$ \\
C (75 mg/kg ROSI, $0.2 \mathrm{ml} / 2$ days) & $4.75 \pm 0.67^{\mathrm{a}, \mathrm{c}}$ \\
D (100 mg/kg ROSI, $0.2 \mathrm{ml} / 2$ days $)$ & $2.25 \pm 0.45^{\mathrm{a}}$
\end{tabular}

${ }^{\mathrm{a}} \mathrm{p}<0.0001$, compared with group $\mathrm{A} ;{ }^{\mathrm{b}} \mathrm{p}<0.0001$, compared with group $\mathrm{C}$ and $\mathrm{D} ;{ }^{\mathrm{c}} \mathrm{p}<0.0001$, compared with group D. ROSI, rosiglitazone; LVD, lymphatic vessel density.

Effects of ROSI on the lymphangiogenesis of gastric cancer. Immunohistochemical staining assays demonstrated that there was a significantly different expression of D2-40 between control group and treatment groups, with the highest level of expression for D2-40 being found in the control group with normal saline (group A) and the lowest in the treatment group with ROSI at $100 \mathrm{mg} / \mathrm{kg} / 2$ days (group D). The typically D2-40-positive vessels (lymphatic vessels) in the control group were evidently more than those in the treatment group. These outcomes indicated that ROSI inhibited the lymphangiogenesis of human gastric cancer transplanted in nude mice in a dose-dependent manner. The representative microscopic view of the immunohistochemical staining for LVD using D2-40 antibody in nude mice treated with normal saline and different 
A

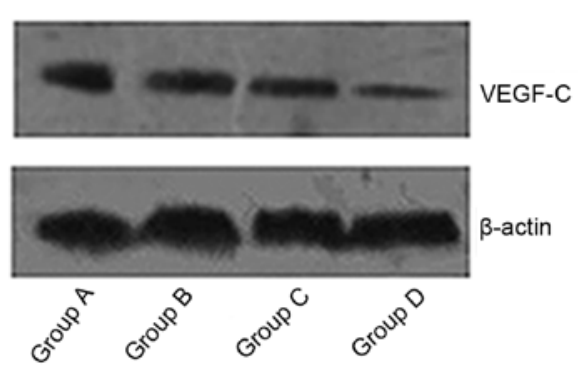

C

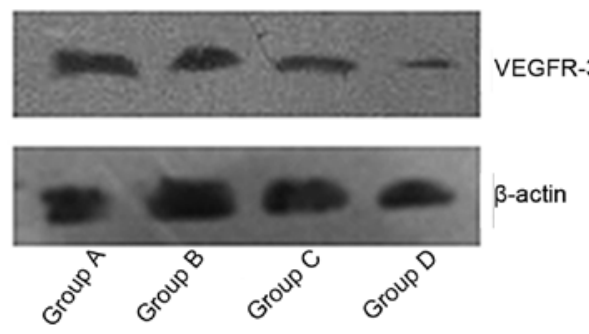

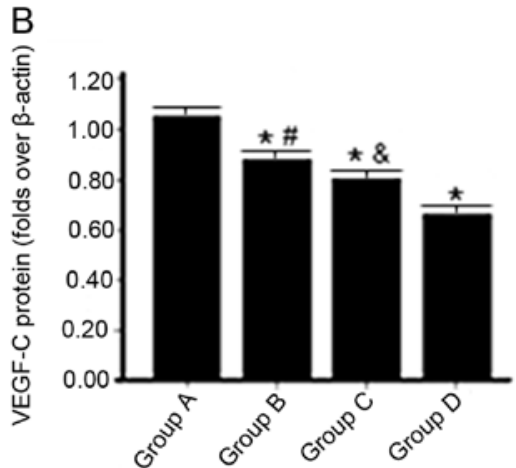

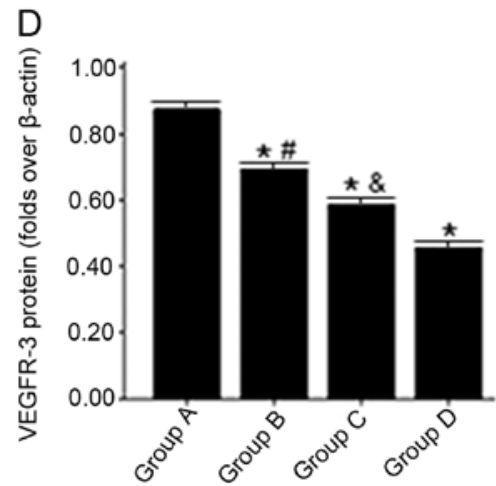

Figure 4. Effects of rosiglitazone (ROSI) on the VEGF-C and VEGFR-3 protein expressions of gastric cancer. One day after inoculation of tumor cells, mice were randomly divided into 4 groups and respectively treated with normal saline (group A), ROSI $50 \mathrm{mg} / \mathrm{kg} / 2 \mathrm{days}$ (group B), ROSI $75 \mathrm{mg} / \mathrm{kg} / 2 \mathrm{days}$ (group C) or ROSI $100 \mathrm{mg} / \mathrm{kg} / 2$ days (group D) for 42 days. After 42 days, the VEGF-C and VEGFR-3 proteins of gastric cancer tissues in nude mice were determined by western blot assay. (A) Western blot assays for VEGF-C protein expressions in every group. Blots were processed using an ECL kit and exposed to X-ray film. (B) Densitometric analyses of the VEGF-C protein expressions. Results are expressed as folds increase over $\beta$-actin. The bar represents the means \pm SD ( $=8$ ). ${ }^{*} \mathrm{p}<0.0001$, vs. group A; ${ }^{\#} \mathrm{p}<0.0001$, vs. group C and D and ${ }^{\star} \mathrm{p}<0.0001$, vs. group D. (C) Western blot assays for VEGFR-3 protein expressions in every group. Blots were processed using an ECL kit and exposed to X-ray film. (D) Densitometric analyses of the VEGFR-3 protein expressions. Results are expressed as folds increase over $\beta$-actin. The bar represents the means $\pm \mathrm{SD}(\mathrm{n}=8)$. ${ }^{*} \mathrm{p}<0.0001$, vs. group A; ${ }^{*} \mathrm{p}<0.0001$, vs. group C and $\mathrm{D}$ and ${ }^{\&} \mathrm{p}<0.0001$, vs. group $\mathrm{D}$. VEGF-C, vascular endothelial growth factor C; VEGFR-3, VEGF receptor-3.

ROSI dose at a magnification of $\mathrm{x} 400$ is illustrated in Fig. 3, and the average value of D2-40-positive vessels in 5 hot spot areas at $\times 200$ magnifications (LVD) is summarized in Table II.

Effects of ROSI on the VEGF-C and VEGFR-3 protein expressions of gastric cancer. Western blot analysis (Fig. 4A and B) showed that the expressions of VEGF-C proteins were clearly inhibited in nude mice treated with ROSI when compared to that in nude mice treated with normal saline after 42 days of transplantation. Moreover, with the increasing doses of ROSI, the inhibitory effects of ROSI on VEGF-C proteins were more significant.

Similarly, Fig. 4C and D showed that the expression levels of VEGFR-3 protein were also gradually decreased with the ROSI dose.

Effects of ROSI on the VEGF-C and VEGFR-3 mRNA expressions of gastric cancer. We further performed RT-PCR analysis for VEGF-C and VEGFR-3 mRNA expression of human gastric cancer transplantation in nude mice.

Consistent with VEGF-C protein expression, Fig. 5A and B showed that the expression levels of VEGF-C mRNA in nude mice treated with ROSI were significantly lower than in nude mice treated with normal saline after 42 days of transplantation. Furthermore, with the increase of ROSI doses, the decrease of VEGF-C mRNA levels was more significant.
Fig. 5C and D show that the expression levels of VEGFR-3 mRNA, also consistent with the expression of VEGFR-3 protein, were gradually reduced with the ROSI dose.

\section{Discussion}

In the present study, we investigated the effects of ROSI on the growth and lymphangiogenesis of human gastric cancer transplanted in nude mice. Our study demonstrated that nude mice treated with different doses of ROSI had significantly decreased tumor growth, clear histomorphological changes and less lymphangiogenesis when compared with those treated with normal saline. Furthermore, VEGF-C and VEGFR-3 expressions in nude mice treated with different ROSI dose were significantly lower than in nude mice treated with normal saline. These results indicated that ROSI had inhibitory effects on the growth and lymphangiogenesis of human gastric cancer, and these effects may be mediated through modulation of VEGF-C and VEGFR-3 expression.

PPARs are ligand-activated transcription factors that belong to the nuclear hormone receptor superfamily (22). They control several cellular and metabolic processes. Three subtypes, PPAR $\alpha$, PPAR $\beta / \delta$ and PPAR $\gamma$, have been identified. Of these, PPAR $\gamma$ is considered a key regulator of adipocyte differentiation (23-25), and plays an important role in the induction of apoptosis, inhibition of tumor cell growth and 

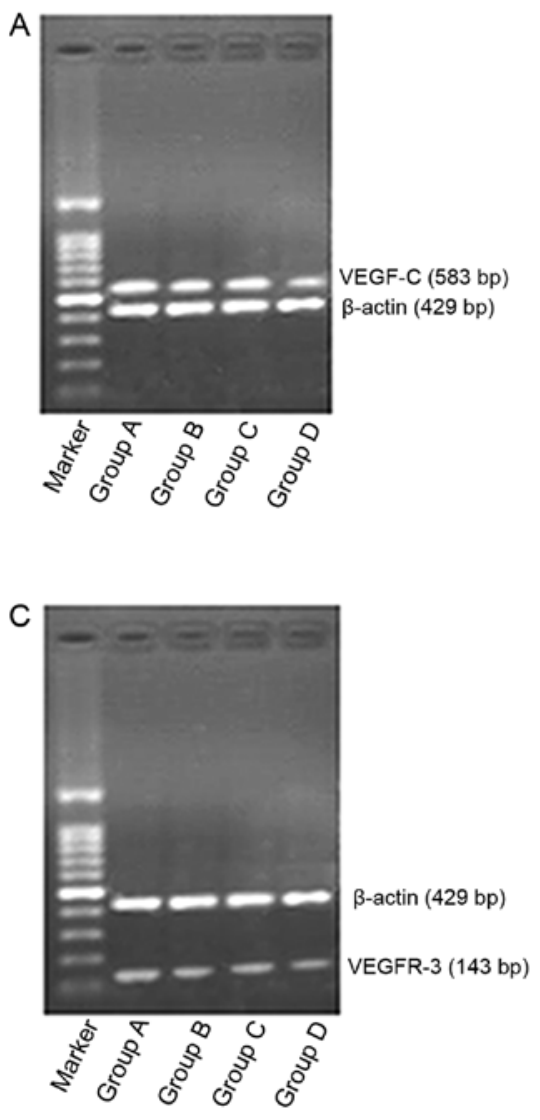

B

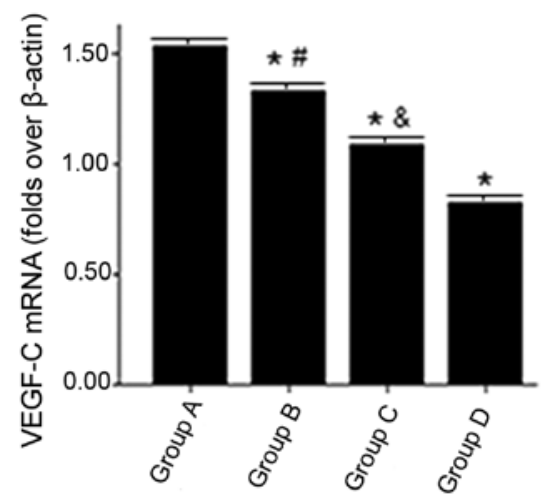

D

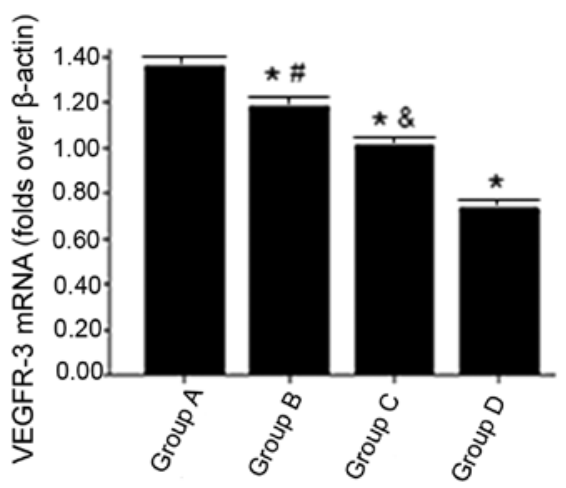

Figure 5. Effects of rosiglitazone (ROSI) on the VEGF-C and VEGFR-3 mRNA expressions of gastric cancer. One day after inoculation of tumor cells, mice were randomly divided into 4 groups and respectively treated with normal saline (group A), ROSI $50 \mathrm{mg} / \mathrm{kg} / 2$ days (group B), ROSI $75 \mathrm{mg} / \mathrm{kg} / 2$ days (group C) or ROSI $100 \mathrm{mg} / \mathrm{kg} / 2$ days (group D) for 42 days. After 42 days, the VEGF-C and VEGFR-3 mRNA of gastric cancer tissues in nude mice were determined by RT-PCR. (A) RT-PCR for VEGF-C mRNA expressions in every group. PCR products (583 bp for VEGF-C and 429 bp for $\beta$-actin) in a $1.5 \%$ agarose gel were stained with ethidium bromide.(B) Densitometric analyses of the VEGF-C mRNA expressions. Results are expressed as folds increase over $\beta$-actin. The bar represents the means $\pm \mathrm{SD}(\mathrm{n}=8)$. ${ }^{\mathrm{p}} \mathrm{p}<0.0001$, vs. group $\mathrm{A} ;{ }^{\#} \mathrm{p}<0.0001$, vs. group $\mathrm{C}$ and $\mathrm{D}$ and ${ }^{\circledR} \mathrm{p}<0.0001$, vs. group D. (C) RT-PCR for VEGFR-3 mRNA expressions in every group. PCR products (143 bp for VEGFR-3 and $429 \mathrm{bp}$ for $\beta$-actin) in a $1.5 \%$ agarose gel were stained with ethidium bromide. (D) Densitometric analyses of the VEGFR-3 mRNA expressions. Results are expressed as folds increase over $\beta$-actin. The bar represents the means $\pm \mathrm{SD}(\mathrm{n}=8)$. " $\mathrm{p}<0.0001$, vs. group A; ${ }^{\mathrm{p}}<0.0001$, vs. group $\mathrm{C}$ and $\mathrm{D}$ and ${ }^{\&} \mathrm{p}<0.0001$, vs. group D. VEGF-C, vascular endothelial growth factor C; VEGFR-3, VEGF receptor-3.

differentiation, inhibition of tumor associated angiogenesis and regulation of immune system $(26,27)$. Perturbed PPAR $\gamma$ signaling has been implicated in the formation of various solid tumors, such as breast, stomach, colorectal and thyroid carcinomas (28-32). Therefore, PPAR $\gamma$ and its ligands have been extensively evaluated as potential molecular targets for anticancer drug development in the past several years.

TZDs, including ROSI, troglitazone and pioglitazone, are synthetic PPAR $\gamma$ ligands. Previous studies have demonstrated that TZDs could inhibit gastric cancer cell line growth $(10,33)$. In addition, $\mathrm{Lu}$ et al (34) found that PPAR $\gamma(+/-)$ mice were more susceptible to N-methyl-N-nitrosourea-induced gastric cancer than wild-type (+/+) mice, and troglitazone significantly reduced the incidence of gastric cancer in PPAR $\gamma(+/+)$ mice but not in PPAR $\gamma(+/-)$ mice. These results suggested that through PPAR $\gamma$-dependent mechanism, TZDs inhibited gastric cancer cell growth. In the present study, we established a model of gastric cancer by subcutaneously inoculating human gastric cancer cell line SGC-7901 into nude mice and found that all the ROSI treatment groups had smaller tumor volume and higher tumor growth inhibitory rate when compared with the control group every day. Moreover, the number of typical tumor cells in the control group was more than that in ROSI treatment groups. Markedly, the inhibitory effect of ROSI on the growth was more significant in the higher ROSI doses. These findings were consistent with previous studies $(10,33)$, confirming that ROSI was able to inhibit the growth of human gastric cancer.

In gastric cancer, both angiogenesis and lymphangiogenesis are important events related to tumor growth and progression (35-37). In fact, gastric cancer mainly metastasizes via lymphatic vessels (20). Recent evidence suggests that tumor lymphangiogenesis promotes lymphatic metastasis $(6,8,38)$. The induction of lymphangiogenesis in the sentinel lymph node started even before tumor cells had arrived $(6,38)$. Thus, tumor lymphangiogenesis is an important early event of cancer metastasis. However, less focus has been on the role of PPAR $\gamma$ or ROSI on lymphangiogenesis although studies have suggested that ROSI may have significant anticancer activities in various human malignant tumors in vitro and in vivo (10-19). In order to evaluate the effects of ROSI on the lymphangiogenesis of gastric cancer, we performed immunohistochemistry assay for LVD using D2-40 (podoplanin) antibody. D2-40 is a specific and sensitive marker of lymphatic endothelial cells 
and is useful in detecting lymphatic invasion by malignant tumors $(39,40)$. Our data showed that there was a significantly different expression of D2-40 between the control group and treatment groups. The number of LVD in the control group was significantly greater than that in other ROSI treatment groups. This demonstrated that ROSI could inhibit the lymphangiogenesis of human gastric cancer transplanted in nude mice.

Lymphangiogenesis is driven primarily by the VEGF-C and VEGF-D, members of the VEGF family of angiogenic factors. These growth factors specifically activate their cognate receptor tyrosine kinase VEGFR-3 located on lymphatic endothelial cells to induce lymphatic capillary proliferation and growth $(41,42)$. Recent studies have demonstrated that VEGF-C/VEGFR-3 axis is actively involved in regulating the migratory and invasive activities of cancer cells $(43,44)$. Of note, the high expression of VEGF-C was found in early gastric cancer patients with lymph node micrometastasis (45). To gain further insight into whether ROSI would affect the expressions of these molecules, we determined the expression changes of VEGF-C and VEGFR-3 mRNA and their proteins in nude mice transplanted with human gastric cancer. Our data demonstrated that the expression levels of VEGF-C protein and mRNA in transplanted gastric tumor tissue were gradually decreased with the ROSI dose. At the same time, the expression levels of VEGFR-3 protein and mRNA were also gradually decreased with the ROSI dose. These results were similar to the study reported by Liu et al (46), who revealed that norcantharidin suppressed lymphangiogenesis in human lymphatic endothelial cells by simultaneously blocking VEGF-C and VEGF-D/VEGFR-3. Collectively, our findings indicated that through simultaneously inhibiting VEGF-C and VEGFR-3 expressions, ROSI blocked the lymphangiogenic signaling and then prevented lymphangiogenesis.

In conclusion, the present study provided evidence that by suppressing VEGF-C and VEGFR-3 expressions, ROSI inhibits the lymphangiogenesis and then inhibits the growth of human gastric cancer transplanted in nude mice, which suggests that ROSI may be an attractive anticancer agent for gastric cancer. However, further studies to clarify the mechanisms by which ROSI downregulates VEGF-C and VEGF-3 expressions in human gastric cancer are required.

\section{Acknowledgements}

We thank Ai-guo Tang and Hui Xie (The Second XiangYa Hospital of Central South University, Changsha, Hunan 410011, China) for reading the manuscript and providing valuable comments.

\section{References}

1. Brenner H, Rothenbacher D and Arndt V: Epidemiology of stomach cancer. Methods Mol Biol 472: 467-477, 2009.

2. Jemal A, Center MM, DeSantis C and Ward EM: Global patterns of cancer incidence and mortality rates and trends. Cancer Epidemiol Biomarkers Prev 19: 1893-1907, 2010.

3. Macdonald JS, Smalley SR, Benedetti J, et al: Chemoradiotherapy after surgery compared with surgery alone for adenocarcinoma of the stomach or gastroesophageal junction. N Engl J Med 345: 725-730, 2001.

4. Achen MG and Stacker SA: Molecular control of lymphatic metastasis. Ann NY Acad Sci 1131: 225-234, 2008.
5. Alitalo K, Tammela T and Petrova TV: Lymphangiogenesis in development and human disease. Nature 438: 946-953, 2005.

6. Mumprecht V and Detmar M: Lymphangiogenesis and cancer metastasis. J Cell Mol Med 13: 1405-1416, 2009.

7. McCarter MD, Clarke JH and Harken AH: Lymphangiogenesis is pivotal to the trials of a successful cancer metastasis. Surgery 135: 121-124, 2004.

8. Matsumoto M, Roufail S, Inder R, et al: Signaling for lymphangiogenesis via VEGFR-3 is required for the early events of metastasis. Clin Exp Metastasis: Apr 17, 2013 (Epub ahead of print).

9. Saltiel AR and Olefsky JM: Thiazolidinediones in the treatment of insulin resistance and type II diabetes. Diabetes 45: 1661-1669, 1996.

10. He Q, Pang R, Song X, et al: Rosiglitazone suppresses the growth and invasiveness of SGC-7901 gastric cancer cells and angiogenesis in vitro via PPAR $\gamma$ dependent and independent mechanisms. PPAR Res 2008: 649808, 2008.

11. Zhang L, Hu JF, Li GQ, Xiao X and Su Q: Rosiglitazone reverses mitomycin C resistance in human gastric cancer cells. Am J Med Sci 343: 382-387, 2012.

12. Talbert DR, Allred CD, Zaytseva YY and Kilgore MW: Transactivation of $\mathrm{ER} \alpha$ by Rosiglitazone induces proliferation in breast cancer cells. Breast Cancer Res Treat 108: 23-33, 2008.

13. Miao $\mathrm{R}, \mathrm{Xu} \mathrm{T}$, Liu L, et al: Rosiglitazone and retinoic acid inhibit proliferation and induce apoptosis in the HCT-15 human colorectal cancer cell line. Exp Ther Med 2: 413-417, 2011.

14. Cerquetti L, Sampaoli C, Amendola D, et al: Rosiglitazone induces autophagy in $\mathrm{H} 295 \mathrm{R}$ and cell cycle deregulation in SW13 adrenocortical cancer cells. Exp Cell Res 317: 1397$1410,2011$.

15. Chiu SJ, Hsaio $\mathrm{CH}$, Tseng $\mathrm{HH}$, et al: Rosiglitazone enhances the radiosensitivity of p53-mutant HT-29 human colorectal cancer cells. Biochem Biophys Res Commun 394: 774-779, 2010.

16. Lyon CM, Klinge DM, Do KC, et al: Rosiglitazone prevents the progression of preinvasive lung cancer in a murine model. Carcinogenesis 30: 2095-2099, 2009.

17. Yee LD, Williams N, Wen P, et al: Pilot study of rosiglitazone therapy in women with breast cancer: effects of short-term therapy on tumor tissue and serum markers. Clin Cancer Res 13: 246-252, 2007.

18. Esteva FJ, Moulder SL, Gonzalez-Angulo AM, et al: Phase I trial of exemestane in combination with metformin and rosiglitazone in nondiabetic obese postmenopausal women with hormone receptor-positive metastatic breast cancer. Cancer Chemother Pharmacol 71: 63-72, 2013

19. Luconi M, Mangoni M, Gelmini S, et al: Rosiglitazone impairs proliferation of human adrenocortical cancer: preclinical study in a xenograft mouse model. Endocr Relat Cancer 17: 169-177, 2010.

20. Dicken BJ, Bigam DL, Cass C, Mackey JR, Joy AA and Hamilton SM: Gastric adenocarcinoma: review and considerations for future directions. Ann Surg 241: 27-39, 2005.

21. Ohno M, Nakamura T, Kunimoto Y, Nishimura K, Chung-Kang C and Kuroda Y: Lymphagenesis correlates with expression of vascular endothelial growth factor- $\mathrm{C}$ in colorectal cancer. Oncol Rep 10: 939-943, 2003.

22. Mangelsdorf DJ, Thummel C, Beato M, et al: The nuclear receptor superfamily: the second decade. Cell 83: 835-839, 1995.

23. Siersbaek R, Nielsen R and Mandrup S: PPAR $\gamma$ in adipocyte differentiation and metabolism - novel insights from genome-wide studies. FEBS Lett 584: 3242-3249, 2010.

24. Nedergaard J, Petrovic N, Lindgren EM, Jacobsson A and Cannon B: PPAR $\gamma$ in the control of brown adipocyte differentiation. Biochim Biophys Acta 1740: 293-304, 2005.

25. Fernyhough ME, Okine E, Hausman G, Vierck JL and Dodson MV: PPAR $\gamma$ and GLUT-4 expression as developmental regulators/markers for preadipocyte differentiation into an adipocyte. Domest Anim Endocrinol 33: 367-378, 2007.

26. Elrod HA and Sun SY: PPAR $\gamma$ and apoptosis in cancer. PPAR Res 2008: 704165, 2008.

27. Kim S, Lee JJ and Heo DS: PPAR $\gamma$ ligands induce growth inhibition and apoptosis through p63 and p73 in human ovarian cancer cells. Biochem Biophys Res Commun 406: 389-395, 2011.

28. Zhou J, Zhang W, Liang B, et al: PPAR $\gamma$ activation induces autophagy in breast cancer cells. Int J Biochem Cell Biol 41: 2334-2342, 2009.

29. Zaytseva YY, Wallis NK, Southard RC and Kilgore MW: The PPAR $\gamma$ antagonist T0070907 suppresses breast cancer cell proliferation and motility via both PPAR $\gamma$-dependent and -independent mechanisms. Anticancer Res 31: 813-823, 2011. 
30. Kitamura S, Miyazaki Y, Hiraoka S, et al: PPAR $\gamma$ inhibits the expression of $c-M E T$ in human gastric cancer cells through the suppression of Ets. Biochem Biophys Res Commun 265: 453-456, 1999.

31. Takahashi H, Hosono K, Uchiyama T, et al: PPAR $\gamma$ ligand as a promising candidate for colorectal cancer chemoprevention: a pilot study. PPAR Res 2010: 257835, 2010. doi: 10.1155/2010/257835.

32. Wood WM, Sharma V, Bauerle KT, et al: PPAR $\gamma$ promotes growth and invasion of thyroid cancer cells. PPAR Res 2011: 171765, 2011. doi: 10.1155/2011/171765.

33. Sato H, Ishihara S, Kawashima K, et al: Expression of peroxisome proliferator-activated receptor (PPAR) $\gamma$ in gastric cancer and inhibitory effects of PPAR $\gamma$ agonists. Br J Cancer 83 : 1394-1400, 2000.

34. Lu J, Imamura K, Nomura S, et al: Chemopreventive effect of peroxisome proliferator-activated receptor $\gamma$ on gastric carcinogenesis in mice. Cancer Res 65: 4769-4774, 2005.

35. Chen J, Zhi Y, Chang X, Zhang S and Dai D: Expression of ADAMTS1 and its correlation with angiogenesis in primary gastric cancer and lymph node metastasis. Dig Dis Sci 58 405-413, 2013

36. Wu H, Xin Y, Xu C and Xiao Y: Capecitabine combined with (-)-epigallocatechin-3-gallate inhibits angiogenesis and tumor growth in nude mice with gastric cancer xenografts. Exp Ther Med 3: 650-654, 2012.

37. Fidler IJ: The biology of cancer metastasis. Semin Cancer Biol 21 : 71, 2011.

38. Al-Rawi MA and Jiang WG: Lymphangiogenesis and cancer metastasis. Front Biosci 16: 723-739, 2011.
39. Raica M, Cimpean AM and Ribatti D: The role of podoplanin in tumor progression and metastasis. Anticancer Res 28: 2997-3006, 2008.

40. Yu JW, Wu JG, Tajima Y, et al: Study on lymph node metastasis correlated to lymphangiogenesis, lymphatic vessel invasion, and lymph node micrometastasis in gastric cancer. J Surg Res 168: 188-196, 2011.

41. Makinen T, Veikkola T, Mustjoki S, et al: Isolated lymphatic endothelial cells transduce growth, survival and migratory signals via the VEGF-C/D receptor VEGFR-3. EMBO J 20: 4762-4773, 2001.

42. Van Trappen PO, Steele D, Lowe DG, et al: Expression of vascular endothelial growth factor (VEGF)-C and VEGF-D, and their receptor VEGFR-3, during different stages of cervical carcinogenesis. J Pathol 201: 544-554, 2003.

43. Su JL, Chen PS, Chien MH, et al: Further evidence for expression and function of the VEGF-C/VEGFR-3 axis in cancer cells. Cancer Cell 13: 557-560, 2008.

44. Takizawa H, Kondo K, Fujino H, et al: The balance of VEGF-C and VEGFR-3 mRNA is a predictor of lymph node metastasis in non-small cell lung cancer. Br J Cancer 95: 75-79, 2006.

45. Arigami T, Natsugoe S, Uenosono $Y$, et al: Vascular endothelial growth factor-C and -D expression correlates with lymph node micrometastasis in pN0 early gastric cancer. J Surg Oncol 99: 148-153, 2009

46. Liu ZY, Qiu HO, Yuan XJ, et al: Suppression of lymphangiogenesis in human lymphatic endothelial cells by simultaneously blocking VEGF-C and VEGF-D/VEGFR-3 with norcantharidin. Int J Oncol 41: 1762-1772, 2012. 